\title{
Mapping as Making Space: The Case of a Nature-Culture Hybrid
}

GI_Forum 2018, Issue 2

Page: 58 - 71

Full Paper

Corresponding Author: rbantjes@stfx.ca

DOI:

10.1553/giscience2018_02_s58

\section{Rod Bantjes}

St. Fra nc is Xa vier University, Antigonish, Canada

\begin{abstract}
The once-settled 'wildemess' region that is the subject of this paper is marked by historic layers of physical inscription and erasure - a nature-culture hybrid that offers a readable surface with temporal depth. In this paper I discuss the mapping of these spatial surfaces as an interpretive and constructive practice. In the process of searching for longabandoned farms in a designated 'wildemess' landscape, my collaborators and I were reading topography and vegetation, aerial photos and archival documents as though all were obscure texts which confronted us with silences, anomalies and uncertainties. In writing up this disc ursive work in the form of an online GIS map hyperlinked to a web of texts and documentary images, I argue that we were both recording and constituting the layers of meaning that make the landscape. I am interested in the subtle power dynamic of such map-making. We were re-reading what the state has designated as 'wildemess' or 'nature' as, instead, non-nature - a cultural artefact. Yet I am sensible of the tension between my collaborators, for whom the map articulates ancestral claims to the landscape, and myself, happy to see the state protect, under the guise of 'wildemess', what I see as a nature-culture hybrid.
\end{abstract}

\section{Keywords:}

c ritic al cartography; nature-culture hybrid; wildemess; Gaelic land memory; story maps

\section{Deep mapping as interpretive practice}

In this paper I will be discussing my methodology for constructing a GIS-based online 'deep map' (Bodenhamer et. al., 2015; Unamuno, 2017) of a small wooded region in the highlands of Antigonish County, Nova Scotia, Canada. My argument in the paper is reflexive, and concerns how a social-science paradigm should, and inevitably does, render even the most 'objective' of mapping exercises interpretive and in some measure constitutive of its object. My method in the paper, then, is theoretically-informed reflection on a particular case of mapping practice.

The 'spatial turn' in the social sciences preceded the 'digital turn' (Urry, 1983, 1987; Soja, 1989). In attempting to give the latter disciplinary shape, Bodenhamer argues that the 
discursive and contested nature of socially-meaningful space demands our continued adherence to reflexive, interpretive methodologies, and disciplinary attention to the effects of power characteristic of humanities and social science practice. 'It will be necessary,' he writes, 'to replace [a] more limited quantitative representation of space with a view that emphasizes the intangible and socially constructed world and not simply the world that can be measured' (Bodenhamer, 2015). The seductive power of the new digital tools draws in the opposite direction, towards the kind of false objectivity that Pitirim Sorokin called 'quantophrenia' (Sorokin, 1956).

My case study is a mapping project that is collaborative and methodologically open, in that reflection on processes of interpreting data sources and representing them as spatial 'realities' are also mapped as part of the published cartographic/textual ensemble (Allen \& Queen, 2015; Cope \& Elwood, 2009). In the map texts, and more explicitly in this paper, I also reflect upon the political interests that shape even the apparently most 'innocent' of mapping practices. That maps can be artefacts in strategies of power is a lesson from critical cartography that has never been more relevant than at the current moment, given the scale of geocoded data collection and the power of atheoretical tools of data mining and predictive analytics being applied to it (Kitchin, Dodge \& Perkins, 2011; Crampton, 2008; Barnes \&Wilson, 2014; Kaplan, 2006; Monmonier, 2002; Thatcher et al., 2015; Leszczynski, 2014). I stand with those in the critical cartography tradition who argue not only that our research practice as map-makers can become implicated in strategies of power, but also, to the extent to which power projects are successfully socially transformative, that our mapping can become simultaneously space-describing and space-making (Allen \& Queen, 2015; Sparke, 1998). I mean this both in a material sense and in the sense of adding interpretive layers of meaning that make up the rich texture of landscapes of meaning.

\section{Mapping a long-abandoned agricultural settlement}

The map that I wish to discuss here began as the most innocent and apolitical of research exercises. I wanted to give my undergraduate students an experience in quantitative research methods using geospatial data. Our research question was whether a once-thriving agricultural settlement, abandoned in the late nineteenth century, had failed for ecological reasons. Our method was to use census data to document changes in agricultural productivity over time and to correlate this data with geospatial data using a GIS map rendered in ArcView.

Our geospatial data included soil quality - whether it was too thin, rocky or poorly drained and topography - in particular whether the slopes in this highland region were too steep and therefore vulnerable to erosion. The topography was given in our GIS base map. We had soil survey maps which we digitized and added as layers. To the soil survey, we intended to add soil samples taken on site. The main tasks were to locate the boundaries of past farms and fields, identify the occupiers of these lands, and finally, by this means to link land-areas to census records. Each of these tasks turned out to be fraught with difficulties of reading and interpretation. The first recalcitrant spatial layer that I want to consider is the census. 


\section{The nineteenth-century census as geopolitics}

Census-taking and map-making were integral to new projects of governance-at-a-distance undertaken by states, beginning in the late eighteenth century (Bantjes, 2005; Carroll, 2006; Curtis, 1989; Rose-Redwood, 2006). These were technologies of surveillance, meant to keep far-flung populations visible and under record. The Scottish and Irish crofters who settled in the highland region of Nova Scotia that was the object of our study had particular reason to be suspicious of such projects. From their perspective, mapping had had an antagonistic purpose in their home countries - overwriting their language of place and facilitating military subjugation and ultimately dispossession (Hewitt, 2010; Ó Cadhla \& Ó Cuív, 2007). While in the New World the state was willing to grant them land, the state's interest in recording where people were located, the number and ages of their children and the extent of their property and possessions was surely resented. What other purpose could motivate such an intrusion but the desire to tax them or send their young men to fight distant wars in the name of the British Crown?

Consider from their perspective the logic of being mapped. The resulting record gives navigational access to outsiders. Locals already know their territory and their people. Their maps are unwritten and remain obscure to outsiders and under local control. Diane George describes the particular cultural mapping practices of these people as "Gaelic "land memory," which embedded territory in genealogy, narrative, and poetry' (George, 2009).

While they gave their names to the census-takers, they withheld an essential key needed to unlock the genealogical code. The Scots settled together as families such that a single surname recurs across a region. More confusingly, as though they recognized generic, collective selves, they reused the same first names with almost equal frequency. It is impossible for an outsider, on the basis of written records, to tell one Hugh Gillis apart from two or three others without the crucial nicknames that people were given or the generational identifiers such as 'Hughie Dan Allan Gillis' where Dan (the father) and Allan (the grandfather) are used to uniquely identify and locate the individual. Thus it became next to impossible for us to determine with certainty who, located on which farm, the census records referred to.

Even had we been able reliably to connect census records to farmed plots, our local informants told us that their ancestors had often deliberately fudged the estimates of their wealth and possessions that they offered the census takers. A politics of resistance was embedded in what otherwise might be mistaken for an 'objective' layer of historical data.

\section{Mapping spatial memory}

Research that began as a class project for students took on a life of its own and extended across many years. I remained attracted to it as much for the process as for its original empirical aims. I became friends with one of my local informants, Charlie Teasdale, and took great pleasure in his inexhaustible capacity to narrate the landscape. As I say in the online version of the map: 
No matter where we were, hacking through underbrush in a deep ravine on Eigg Mountain, or driving down some back road at the other end of the county, and everywhere in between, he had a story to tell about the place. Stories are about people, and talk of people led to genealogy - how people were connected to other people. Charlie would trace these connections, on an astonishingly detailed map in his head, to other places, in Antigonish or adjacent counties as far away as Cape Breton where these people were attached to the land. 'Attached' meant a range of things - a working engagement with, a claim to, or a love of a piece of land.

taverns in Antigonish, so he loaded the carcass onto his wagon as evidence and took it into town where he lived off the tale for two weeks.

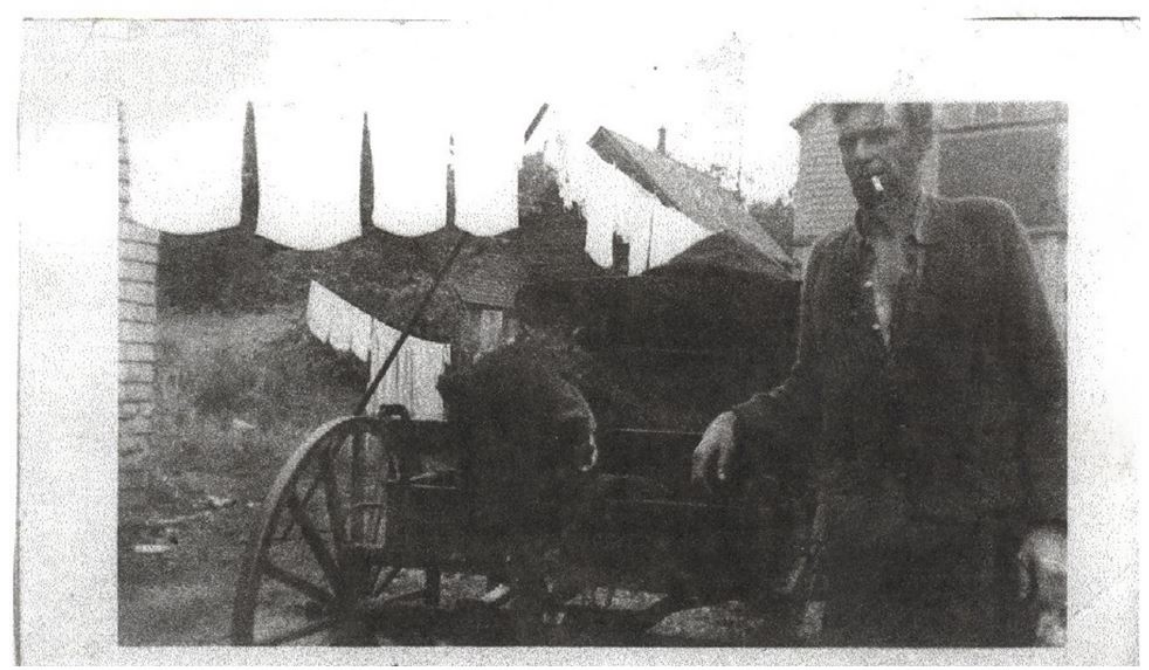

Figure 4 - Photo of Lame Angus with the hapless bear.

Figure 1: Fragment of Map Text: Lame Angus MacEachem, Charlie's great uncle, who killed a bear with a drive shaft

While movement through the landscape would elicit stories, stories drawn from this internal map were also navigational devices. Charlie and I employed completely different navigational paradigms. Mine was a bird's eye view, referenced to a universal grid, oriented to the cardinal points. The 'spatial' bias of this paradigm is only evident in comparison to Charlie's, which was procedural and referenced to temporal narrative lines. I recall one instance when he and I were in a wooded ravine, uncertain of our location. I struggled to picture the contour lines of the map - surveying the structure and number of ravines that were near us and their compass orientation. Charlie struggled to remember and all of a sudden knew, because he had once shot a deer in that place. It was a strong memory because it had been a bad shot and 
the deer had run bleeding for a long distance. Decades of growth had changed the landscape, but the story of pursuing the deer provided us with the path out.

Charlie's skills were a particularly vivid example of what I was later to understand as 'Gaelic land memory'. He recognized that he was one of the last people in the region to retain it, and wanted it preserved. Until he met me, with my GPS and digital mapping skills, he had never been able to imagine how the spatial dimension of his internal story-map could be recorded. That became my new methodological challenge: how to record a temporal-narrative spatial paradigm with tools designed in conformity with a universalistic, atemporal paradigm.

My solution was necessarily partial, but involved producing sets of texts hyperlinked among themselves and hyperlinked from locations on the maps. Names on the map link to an interconnected genealogical 'layer'. The genealogy can lead to other people connected to other places by description and (in a recent version under construction) by hyperlinking back to the map surface. I similarly used hyperlinked texts to render the stories - based both on oral narrative and recorded history. I further sought to represent time on the map surface by adding fields in the geodatabases to record earliest and latest known dates for every person and artefact we mapped. These can in principle be queried by year to represent, in delimited form, specific past surfaces. In practice, gaps in the temporal data mean that such queries often produce thin results, so the expedient solution has been to represent temporally separate features simultaneously, in the way that past and present coexist in land memory or a story map.

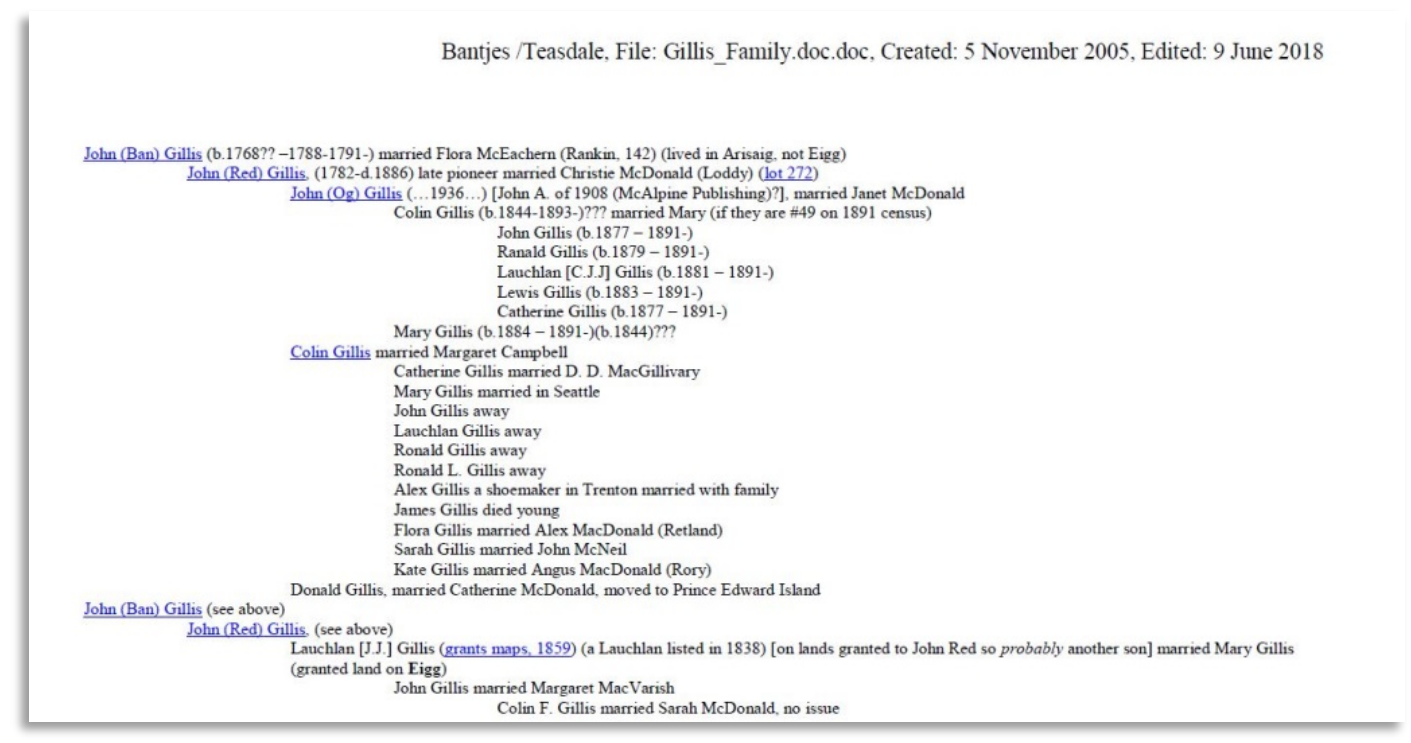

Figure 2: Fragment of a genealogy with hyperlinks 


\section{$5 \quad$ Politics of land claims}

Central to Charlie's narration of the landscape were repeated reference to 'lines', that is, to property boundaries (features of the land often invisible to my eye). Mapping property boundaries was important to do for both conceptions of the project aims and should have been the easiest thing to do 'objectively'. However, the official records from the nineteenth century of land descriptions and land transactions were surprisingly inaccurate and incomplete, and often bore little relation to how people actually used and made claim to the land. The sorry condition of legal records says something about the capacity of the state to define and manage land claims, and, more generally, to govern in places like Eigg Mountain in the nineteenth century.

Nova Scotian surveyors used metes and bounds systems for land description, which were subject to three sources of doubt and indeterminacy. First, the starting point for the description was both relative (i.e. not a determination of latitude and longitude) and often marked by transient features of the landscape. One such description begins 'at birch 16" dia., thence S 84 E 93.00 to fallen maple rampike'. Trees grow (to become wider than 16"), die or are cut down; a 'rampike' is an already-dead tree, its bark fallen off and the wood beneath turned white, dry and brittle. The second problem is the same one that dogged the census. Bounds were defined by the names of surrounding property holders and these names are non-unique and therefore often indeterminate. The third difficulty was that surveyors recorded directions using magnetic north in a region where magnetic north departs from true north by as much as $24^{\circ}$ and, of course, shifts over time. ${ }^{1}$

These 'legal' determinations of property were made in a context where the sovereignty claims of the state were fragile. Treaties signed with the local Indigenous peoples did not explicitly extinguish Indigenous title or sovereignty. This legal indeterminacy has in the twenty-first century become the source of contested land rights. Oral tradition suggests that the Mi'kmaq understood that they were granting something akin to usufruct rights, but not conferring to the British Crown unilateral rights to grant or revoke either rights of use or title (Wicken, 2002). Land-grant surveys and maps were the most fundamental way in which cartography was employed to 'make real' one set of claims in ongoing contestation over social space.

Within the fragile legal framework proposed by the Crown were further grounds for contesting tenure on Eigg Mountain. Would-be settlers were granted title contingent on fulfilling minimal conditions of residency and 'improvement'. However, large swathes of land were also granted as perquisites to absentee owners interested either in speculation or in timber rights. Title to these grants could be retained so long as the grantee, after some unspecified 'reasonable time' and for a period of at least three years, employed 'one able hand, for every hundred acres, in cutting wood'. Further, such timber grants could only be claimed on land deemed to be 'so rocky or stony as not to be fit for culture or pasture'. ${ }^{2}$

\footnotetext{
${ }^{1}$ For a more complete discussion of these methods and the implications for settlers' understandings of their property boundaries, see Bantjes (2015a).

${ }^{2}$ Crown Grant, Book A, page 111.
} 
While documents recording original grants survive, there are few which record whether any of the conditions of title were fulfilled by any of the would-be title holders. Without adequate on-the-spot inspection or systems of record-keeping, the discursive, legal machinery of statedefined property boundaries and title was weak. Settlers who were later able to claim title with sufficient authority to dispose of their lands through legal contract appear to have done so largely on the basis of real occupation and use rather than documentation. By this same logic, absentee claims were rendered largely meaningless, a condition implicitly recognized by settlers who 'squatted' on lands 'legally' granted to others. Their very success in converting the hard soil to agricultural purposes would de-facto invalidate the condition 'not fit for culture and pasture' on which the rival landholder had made claim. So in an interesting way our original research question, 'Was the land fit for cultivation?', was at issue in determining the legal realities of this contested property layer. In addition, settlers' efforts to transform soil quality by burning, removing rock and manuring can be seen as contestations of the state's official mapping of all Eigg Mountain soils as unsuited to cultivation (Cann et. al., 1978). ${ }^{3}$

One might expect that legal texts (land descriptions) and survey maps would act as mappings of space that transform the territory. That is, by granting the right to clear and uproot, build and till within determinate boundaries, they empower the actions of title-holders to 'write' upon the land in physical inscriptions. However on Eigg Mountain the land boundaries 'made real' by settlers were often at odds with the legal inscriptions. The physical evidence of these counter-inscriptions is clearest where rock walls have been built counter to legal boundaries. The new boundaries discernible in walls and field edges are often more rational. They bound the land according to a more 'realist' logic, that is, in accordance with the physical features of the land and its affordances. Good quality soil on level ground was rare, and where 'legal' property boundaries arbitrarily segmented it, the legal lines were simply ignored. Settlers were making space that was meaningful in terms of their daily life practices.

\footnotetext{
${ }^{3}$ Eventually, and despite the difficulty with using census data, we accumulated enough evidence to make a plausible argument with regard to the question of land suitability. See Bantjes (2015b). My conclusion was that 'even without competition from an industrializing economy, even if subsistence were the only option, highland settlements like Eigg Mountain could not have survived for many more generations because, despite their best efforts, farmers were not able to maintain soil fertility.'
} 


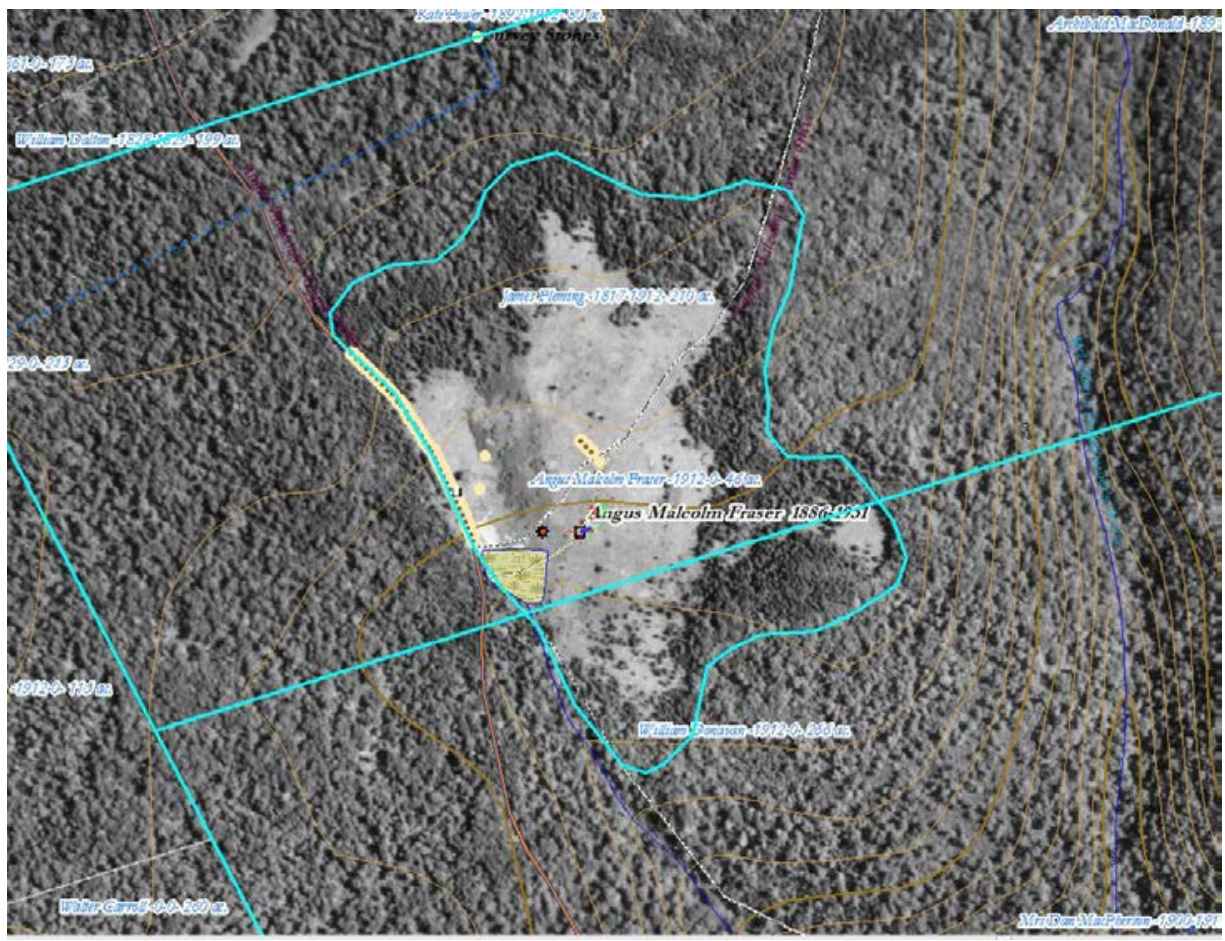

Figure 3: Counter-Inscription of Property Boundaries: the straight lines are the legal boundaries, overlaid/intersected by actual use (the more amorphous shape)

\section{Reading the forested landscape}

These 'real' inscriptions on the land, significant for our project of recovering the layers of meaning that make up this landscape, had, by the time we arrived, been subject to between 80 and 150 years of erasure. What were once open fields and pasture now presented to the unpractised eye a deep primordial forest. I learned, over many years in the woods with Charlie, how to see through this modern surface to the traces of the landscape of centuries past. This 'reading of the forested landscape' (Wessels, 1997) became for me one of the most engaging of methodological challenges.

Clear physical evidence in the form of rock that had been worked in the distant past cleared from fields and piled in mounds, arranged in linear 'walls' or carefully fitted in cellar and foundation walls - was rare and incomplete. Other signs were available in the form of the ground surface and subtle variations in vegetation. Abandoned fields are typically colonized first by white spruce. An even-aged stand of white spruce covering level, mossy ground was sure evidence of a former field. We came to experience such places not so much conceptually, as evidence, but rather perceptually, as the visual presence of a former landscape. Pit and mound topography, caused by a blow-down of a mature forest, was, unless evidently recent, a good sign of land that had never been ploughed. There are kinds of evidence, more difficult to put into words, that help distinguish a pasture from the 
intensively-manured and cultivated lands close to the dwelling on which vegetables and other food crops were grown. Settlers physically reshaped surfaces but also chemically transformed soils in ways that are still dimly visible in botanical signatures over a century later. In learning how to read these signatures we were changing our perceptual abilities, seeing through the present landscape to the ghosts of the past - just as when one reads text one no longer sees words, but the ideas that the words represent.

\section{Field of Archie the Widow MacIsaac (Eigg Mountain Settlement History)}

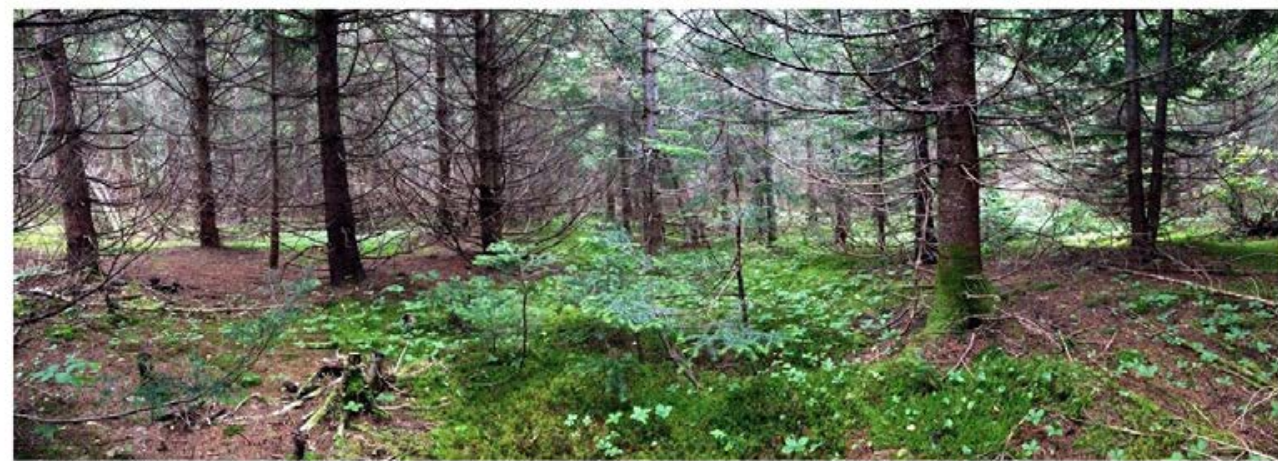

Figure 1 - Panorama of a former field overgrown with white spruce. August 9, 2015.

\section{Figure 4: Illustration from map text}

The readable surface was a palimpsest - subject to erasures and re-inscriptions throughout the different eras of forestry practice that followed agricultural settlement. I should point out that my reading moved back and forth between the land and a series of 1945 aerial photographs that I had georeferenced to the base map. These photos show the marks of steam-driven saw mills, sawdust piles (which can be confused with collapsed buildings) and the first clear-cuts. A series of interpretive problems arose concerning, for example, how to read the difference between an area cut only for forestry versus an area cut for fields versus an area cut and re-cut for different purposes. Bulldozers, which began to be employed in the 1950s and 60s, obscured and complicated reading on the ground - deceptively piling rocks, digging depressions, carving roads and filling in cellars.

The perplexities of interpretation became topics of discussion and debate. One of the issues that divided Charlie and me for a long time was the question of whether hardwood stands ruled out the presence of former fields. That debate was finally resolved by evidence of rock piles, indicating cleared land, located in three cases under pure hardwood stands. In the process we acquired a new marker of time, since two successive generations of re-growth, from softwood to hardwood, would have had to occur on such lands. 


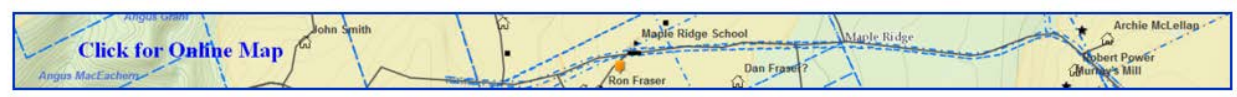

\section{Hardwood over Field (Eigg Mountain Settlement History)}

This is the lower field of "the hermit" and is an example of a former field growing over in hardwood. The view (Figure 1) is looking east across the field from its western boundary (defined by rock piles like the one below (Figure 2)). The hardwood is second growth. The large stumps are from old softwood trees that originally grew up on the field which was probably abandoned in the early $20^{\text {th }}$ century. This portion of the field is overgrown in the 1945 aerial photo.

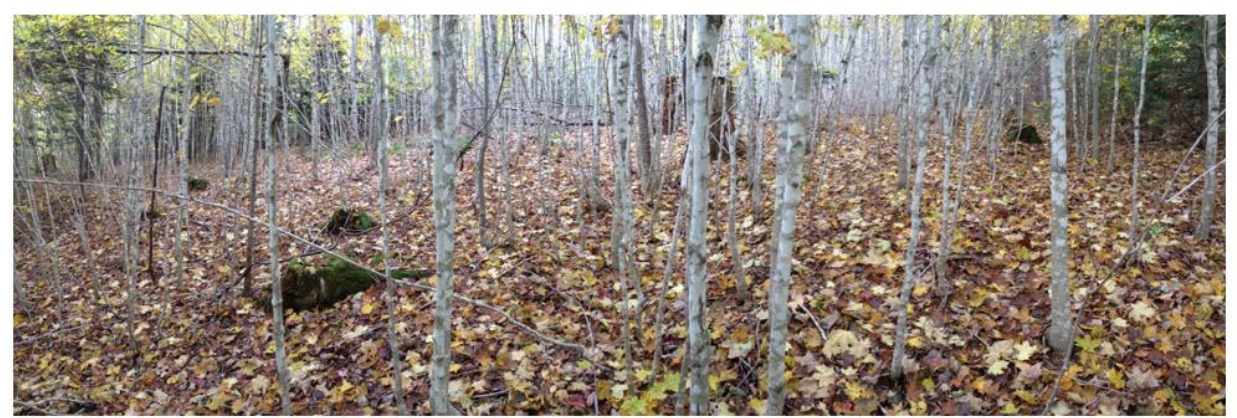

Figure 1 - Panorama of Young Hardwood Stand

Figure 5: Selection from map text

This reflexive discourse, both the reading and the meta-discourse on how to read, was to my mind the richest layer of meaning that we uncovered and the one that most 'attached' me to the landscape. It, too, became a layer that I sought to map through the hyperlinked texts that make up the online assemblage of layers. These texts include evidence such as reproductions of the georeferenced aerial photographs and historic maps, photographic documents of topography and physical artefacts, some of them in stereo 3D form, along with reflections on the interpretation of evidence.

\section{The nature-culture hybrid}

In reading the forested landscape, we were penetrating below a surface that looked to the untrained eye like wilderness or nature, in order to reveal the marks of culture. We were rereading 'nature' as a cultural artefact. This was interesting to me in the context of current debates about the status of the very concept of nature in the emergent era of the Anthropocene (Steffen et al., 2007; Morton, 2007; Castree \& MacMillan, 2001; Cronon, 1996). I came to understand Eigg Mountain as a concrete but subtle instance of a natureculture hybrid. It offered a valuable site for field trips - allowing my students to appreciate 
experientially some of the abstract concepts they were reading about in theoretical literature. The concept of a nature-culture hybrid recognizes the 'agency' of natural 'actants' (Latour, 2004). Humans have carved out artefactual spaces from the forest. What has grown back and the way that that re-growth has reshaped those human interventions is determined by the biological logic of the indigenous and introduced species. The actants respond to and build upon each other's interventions.

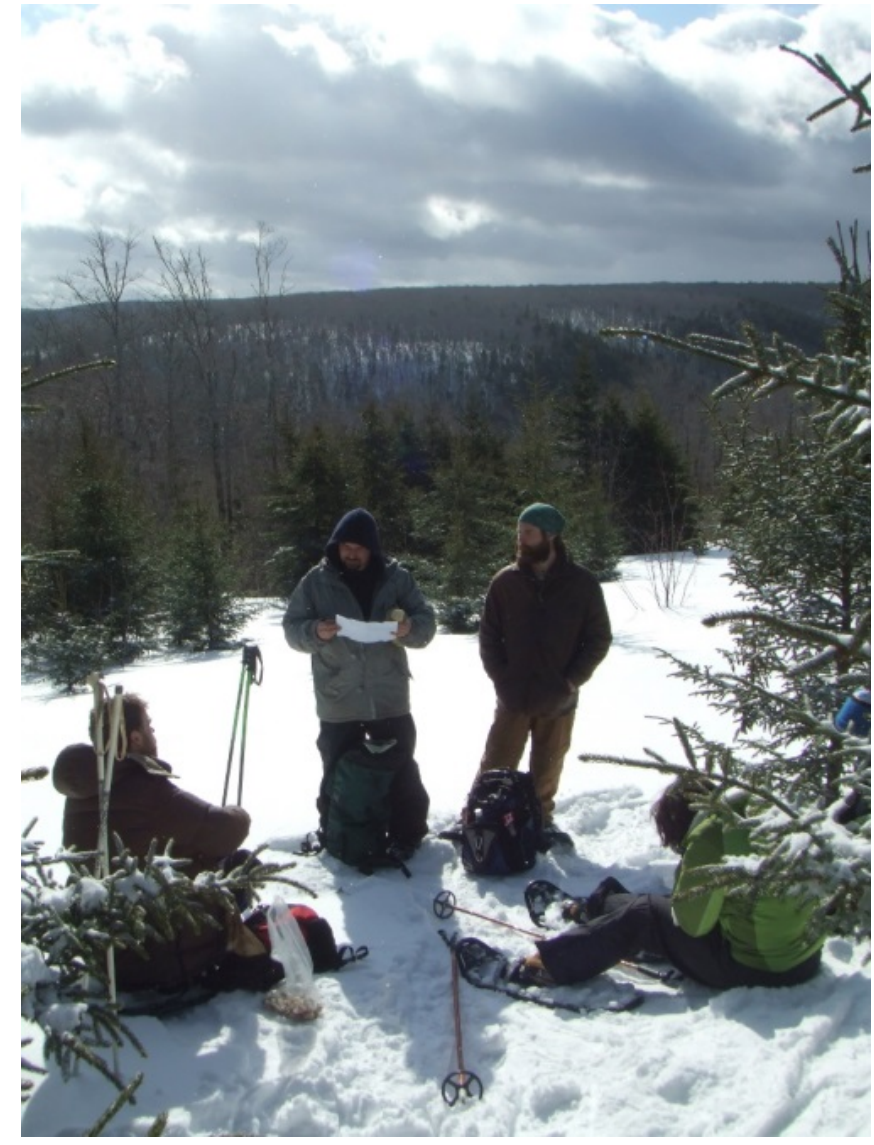

Figure 6: Students contemplate Eigg Mountain 'wildemess' from a fomer field overlooking traditional Mi'kmaq hunting grounds, 2009.

Not all of my preoccupations were shared by my collaborators. We worked together but brought slightly different aims and expectations to the project. Descendants of the settlers understandably wished to memorialize the accomplishments of their ancestors. This aim is achieved through the narrative layers of the map that document the toil and resilience, solidarity and good humour of the settlers, layers that also correct some of the historical misconceptions about the sophistication of their agricultural practices and their capacity to innovate and adapt (Gentilcore, 1956). Still, there has always been the stubborn fact of the abandonment of the Eigg Mountain settlement and the failure of dreams that that seems to imply. On this issue I have had to tread a fine line between, on the one hand, my genuine respect for the people I was working with and for the pioneers whose lives I was recording, 
and, on the other, my assessment of the weight of evidence. The two were in tension over the questions of the legal status of many of the land claims of settlers, and the long-standing and implicit settler-state dispute over whether the land had indeed been sustainably arable.

The other agenda was a residual hope, tentatively advanced in the later years of our collaboration, of the possibility re-asserting claim to the land. Some of the descendants of the settlers felt that the state had somehow cheated their ancestors in the transactions by which the Province re-conveyed land back to the Crown. Provincial Departments of Agriculture and Forestry had, since the early twentieth century, been making a case that marginal lands such as those on Eigg Mountain were permanently unsuited to agriculture, and indeed had been damaged by imprudent agricultural settlement. Lands on Eigg Mountain began to be abandoned in the mid-nineteenth century and were largely empty of settlers by the early twentieth century. Abandoned lands were either sold at auction or reclaimed by the Crown on the grounds of unpaid tax arears. But the Crown was increasingly motivated by a larger agenda of retiring all such lands from cultivation.

In the twentieth-first century, the Province, in response to commitments to expand ecological reserves, officially designated much of Eigg Mountain as a 'wilderness protected area'. Many local people harbour resentment about the restrictions on land access and use that came with the official designation. Our map can be read as a reminder that what the state insists is 'wilderness' is actually a cultural artefact upon which claims of use have not been fully extinguished. While I do not support resistance to the current protected status of Eigg Mountain, or the reinforcement or expansion of that protection, I have to recognize that it is one layer of meaning embedded in, and indeed engendered by, the mapping project that I facilitated. It is a final reminder that maps are not only multi-level interpretive constructs, but that they participate in the social dynamics of power and contestation whose effects, or at least whose hoped-for effects, can include reshaping the world that they map.
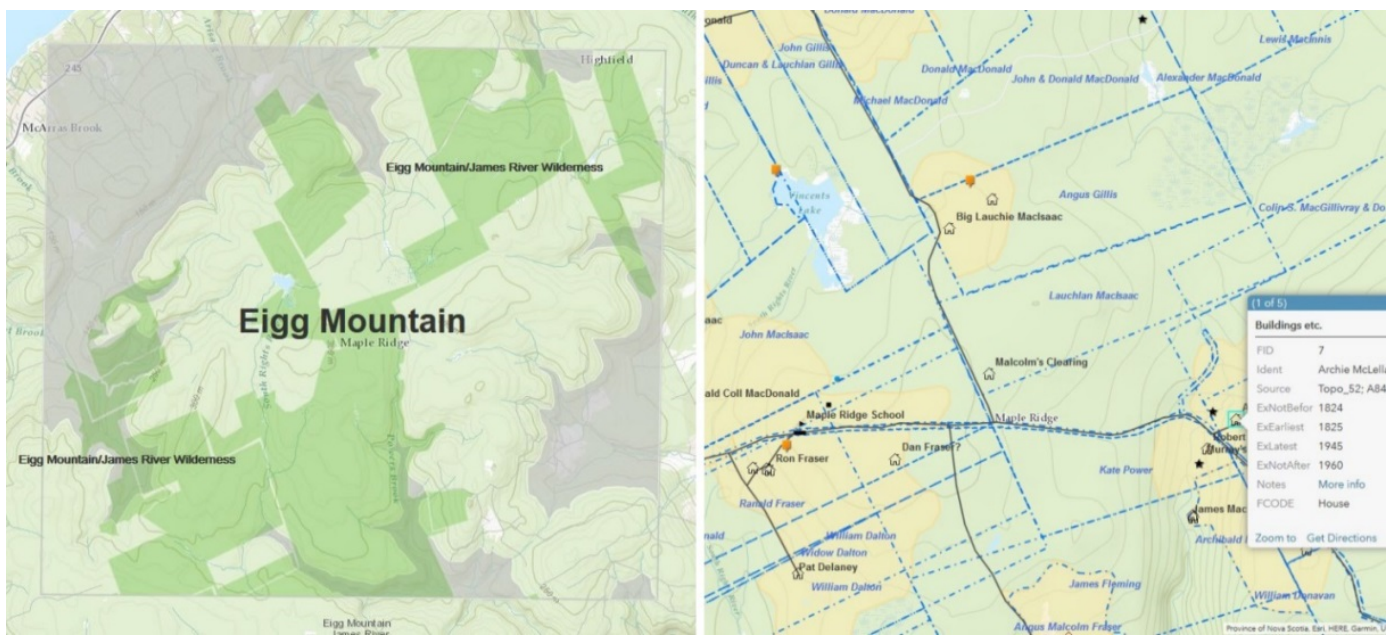

Figure 7: Online version of the map (http://arcg.is/1SajvG): full extent and zoom to detail. 


\section{Conclusion}

Using the Eigg Mountain mapping project as an example, I have argued that what we take to be 'innocent', objective data to be mapped - land grant maps, soil survey maps, census data - often have embedded within them the outcomes of social contestations of power. There is a reified politics embedded here, concerning what the land was, and who successfully could make claim to it. (A notable silence in this data is the spatial knowledge of Indigenous people who used these lands for winter hunting grounds - their place names, pathways and stories are absent.) I have also demonstrated that research questions that might seem of purely 'scientific' curiosity (did soil-fertility decline lead to the abandonment of a settlement?) can turn out to be fraught with political significance. Finally, I have used my case study to show that, in addition to the reified politics embedded in history, we inevitably find that our own mapping practice implicates us in live, ongoing struggles over social space. In my case, it was the contested question of whether Eigg Mountain could be re-inscribed on the map as 'wilderness'.

\section{References}

Allen, T., \& Queen, S. (2015). Beyond the map: Unpacking critical cartography in the digital humanities. Visible Language, 49(3), 79-98.

Bantjes, R. (2005). Improved Earth: Prairie space as modern artefact, 1869-1944. Toronto: University of Toronto Press.

Bantjes, R. (2015a). Making Claim to the Land. Retrieved from http://people.stfx.ca/rbantjes/gis/txt/eigg/Making_Claim.html

Bantjes, R. (2015b). Eigg Mountain Soil Fertility. Retrieved from http://people.stfx.ca/rbantjes/gis/txt/eigg/Soil_Fertility.html

Barnes, T. J., \& Wilson, M. W. (2014). Big data, social physics, and spatial analysis: The early years. Big Data \& Society, 1(1), 2053951714535365. doi:10.1177/2053951714535365

Bodenhamer, D. J. (2015). Narrating place and space. In D. J. Bodenhamer, J. Corrigan, \& T. M. Harris (Eds.), Deep maps and spatial narratives. Bloomington: Indiana University Press.

Bodenhamer, D. J., Corrigan, J., \& Harris, T. M. (2010). The spatial humanities: GIS and the future of bumanities scholarship. Bloomington: Indiana University Press.

Bodenhamer, D. J., Corrigan, J., \& Harris, T. M. (2015). Deep maps and spatial narratives. Bloomington: Indiana University Press.

Cann, D. B., Hilchey, J. D., Canada, \& Nova Scotia. (1978). Soil survey of Antigonish County, Nova Scotia. Ottawa; Halifax: Agriculture Canada; Dept. of Agriculture and Marketing.

Cope, M., \& Elwood, S. (2009). Qualitative GIS: a mixed methods approach. London: SAGE.

Carroll, P. (2006). Science, culture, and modern state formation. Berkeley: University of California Press.

Castree, N., \& MacMillan, T. (2001). Dissolving dualisms: Actor-networks and the reimagining of nature. In N. Castree \& B. Braun (Eds.), Social nature theory, practice, and politics. Malden, MA: Blackwell Publishers.

Crampton, J. (2008). The role of geosurveillance and security in the politics of fear. In D. Z. Sui (Ed.), Geospatial technologies and homeland security: Research frontiers and future challenges. Dordrecht: Springer.

Cronon, W. (1996). The trouble with wilderness; or, getting back to the wrong nature. In W. Cronon (Ed.), Uncommon ground: Retbinking the human place in nature. New York: W.W. Norton \& Co.

Curtis, B. (1989). Representation and state formation in the Canadas, 1790-1850. Studies in Political Economy, 28, 59-87. 
Gentilcore, R. L. (1956). The agricultural background of settlement in eastern Nova Scotia. Annals of the Association of American Geographers, 46, 378-404.

George, D. F. (2009). Colonization by documentation: British representations of Ireland in maps, archives, and travelogues. Radical History Review, 2009(104), 153-158. doi:10.1215/01636545-2008073

Gregory, I. N., \& Geddes, A. (2014). Toward spatial humanities: Historical GIS and spatial history. Bloomington: Indiana University Press.

Hewitt, R. (2010). Map of a Nation: A biography of the ordnance survey. London: Granta.

Kaplan, C. (2006). Precision targets: GPS and the militarization of U.S. Consumer identity. American Quarterly, 58(3), 693-713,983.

Kitchin, R., Dodge, M., \& Perkins, C. R. (2011). Introductory essay: Power and the politics of mapping. In M. Dodge, R. Kitchin, \& C. R. Perkins (Eds.), The Map Reader: Theories of mapping practice and cartographic representation. Oxford: Wiley-Blackwell.

Leszczynski, A. (2014). On the Neo in Neogeography. Annals of the Association of American Geographers, 104(1), 60-79. doi:10.1080/00045608.2013.846159

Monmonier, M. S. (2002). Spying with Maps: Surveillance technologies and the future of privacy. Chicago: University of Chicago Press.

Morton, T. (2007). Ecology without Nature: Rethinking environmental aesthetics. Cambridge: Harvard University Press.

Ó Cadhla, S. N., \& Ó Cuív, E. A. (2007). Civilizing Ireland: Ordnance survey 1824-1842 : Ethnography, cartography, translation. Dublin: Irish Academic Press.

Rose-Redwood, R. S. (2006). Governmentality, geography, and the geo-coded world. Progress in Human Geography, 30(4), 469-486. doi:10.1191/0309132506ph619oa

Smyth, W. J. (2006). Map-making, landscapes and memory: A geography of colonial and early modern Ireland, c.1530-1750. Cork: Cork University Press in association with Field Day.

Soja, E. W. (1989). Postmodern Geographies: The reassertion of space in critical social theory. London: Verso.

Sorokin, P. A. (1956). Fads and foibles in modern sociology and related sciences. Chicago: H. Regnery Co.

Sparke, M. (1998). A map that roared and an original atlas: Canada, cartography, and the narration of nation. Annals of the Association of American Geographers, 88(3), 463-495. doi:10.1111/00045608.00109

Steffen, W., Crutzen, P. J., \& McNeill, J. R. (2007). The Anthropocene: Are humans now overwhelming the great forces of nature? Ambio, 36(8), 614-621.

Thatcher, J., et al. (2015). Revisiting critical GIS. Environment and Planning A: Economy and Space, 48(5), 815-824. doi:10.1177/0308518X15622208

Unamuno, E. S. (2017). GIS and telescopic reading: Between spatial and digital humanities. Neohelicon, 44(1), 65-81. doi:10.1007/s11059-017-0381-1

Urry, J. (1983). Some notes on realism and the analysis of space. International Journal of Urban and Regional Research, 5, 122-127.

Urry, J. (1987). Nature and society: The organization of space. In R. A. A. J. Hughes (Ed.), Classic Disputes in Sociology. London: Allen \& Unwin.

Wessels, T. (1997). Reading the Forested Landscape: a natural bistory of New England. Woodstock, VT: Countryman Press.

Wicken, W. C. (2002). Mi'kmaq treaties on trial: History, land and Donald Marshall Junior. Toronto: University of Toronto Press. 